\title{
Archimedes' Principle - Internet Accessible Remote Experiment
}

\author{
http://dx.doi.org/10.3991/ijoe.v10i5.3831 \\ M. Ožvoldová ${ }^{1,2}$, P. Špiláková 2 and L. Tkáć 1 \\ ${ }^{1}$ Trnava University in Trnava/Faculty of Education, Trnava, Slovak Republic \\ ${ }^{2}$ University of Tomas Bata in Zlín/Faculty of Applied Informatics, Zlín, Czech Republic
}

\begin{abstract}
The development of new information technologies is enabling remote experimentation, a common practice in university education. This contribution describes the procedure of developing the remote experiment-the Archimedes' Principle-using the Internet School Experimental System (ISES) for hands on experimentation and Easy Remote ISES software for transformation of this experiment to a remote one, applied for the first time. The experiment consists of the mobile platform with controlled and measured displacement, on which were placed three vessels with liquids. The bodies were suspended from the ISES dynamometers, measuring the resulting suspension force when they were dipped into liquid. The simultaneous measurement of the suspension force enabled recording of the weight, total force or buoyancy force alone. The experiment is available on http://remotelab9.truni.sk as a part of e-laboratory in Trnava, Slovakia (http://kf.truni.sk/remotelab).
\end{abstract}

Index Terms-Archimedes' Principle, Easy Remote ISES, remote experiment, remote laboratories.

\section{INTRODUCTION}

The necessity of pupils' / students' experimental work in laboratories has always been an important aspect of the educational process of teaching natural sciences, where experiments play a decisive role. But many schools in various parts of the world have very poor or no laboratories, so the teachers have to use their own equipment and replace the students' experimental work with simple demonstration experiments. Sometimes teachers even omit the experimental activity and explain the theory without real demonstrations. Fortunately, teachers now have another option for how to conduct experiments without extensive technical support. Rapid development of the Information and Communication Technologies (ICT) has made it possible to build elaboratories with experiments that can be controlled from everywhere by a computer via the Internet. During the last fifteen years, virtual and remote e-laboratories have become a common feature of university education throughout the world. But remote laboratories are currently being paid increased attention in the wider society. Their numbers are growing, although it is not easy to create an interface for remote experiments.

Easy Remote Internet School Experimental System (ER ISES) [1] was developed to facilitate the creation of interfaces for remote communication between the experimenter and the experimental device. It is also userfriendly for non-programmers, who can now easily design a variety of remote experiments. The current contribution introduces the ER ISES application via an example of the procedure used in developing an Archimedes' Principle remote experiment, using the above-mentioned environment for the first time.

\section{ARCHIMEDES OF SYRACUSE}

An account of the life of Archimedes was written by Heracleides, but this biography has not survived and the particulars, as are known, have been collected from many various sources. Archimedes was the son of Phidias, an astronomer, and was a friend and kinsman of King Hieron of Syracuse and his son Gelon. Archimedes was a Greek mathematician, engineer, physicist, astronomer and inventor.

Just about the most famous story about him is the story of the crown made for King Hieron. It was suspected that the new crown was not wholly made of gold but contained an admixture of silver. Heiron put to Archimedes the problem of determining the proportions in which the metals were mixed. Archimedes discovered the solution to this problem during his bath. Archimedes supposedly was so thrilled with his discovery that he immediately hopped out of the bath and ran naked through the streets, shouting 'Eureka!' ("I have found it!") [2].

But it seems more likely that the actual discovery was made by a more elementary method described by Vitruvius. If Archimedes stepped into the bath when it was full, a volume of water was spilt equal to the volume of his body. He thought of applying the same idea to the case of the crown and measuring the volumes of water displaced. In next step he measured the volumes of water by the same weight of pure gold and by the same weight of pure silver. Now suppose the weight of the crown is $M$, and that it contains weights $M_{\mathrm{g}}$ and $M_{\mathrm{s}}$ of gold and silver. The volume of water the crown itself displaces is $V$, weight $M_{\mathrm{g}}$ of gold displaces a certain volume of water $V_{\mathrm{g}}$ and weight $M_{\mathrm{s}}$ of silver displaces a certain volume of water $V_{\mathrm{s}}$.

From it follows, by proportion, that a weight $M_{\mathrm{g}}$ of pure gold will displace $\frac{M_{g}}{M} V_{g}$ of the water and a weight $M_{\mathrm{s}}$ of silver displaces $\frac{M_{S}}{M} V_{S}$ of the water.

$$
\begin{gathered}
\quad H=\frac{M_{g}}{M} V_{g}+\frac{M_{S}}{M} V_{S} \rightarrow \\
\frac{M_{g}}{M_{S}}=\frac{V_{S}-V}{V-V_{g}}
\end{gathered}
$$

Equation (1) gives the required ratio of the weights of gold and silver contained in the crown [2].

This discovery is known as Archimedes' Principle and states that the magnitude of the buoyant force always 
equals the weight of the fluid displaced by the object. The buoyant force acts vertically upward through the point that was the center of gravity of the displaced fluid [3].

\section{INTERNET SCHOOL EXPERIMENTAL SYSTEM}

Authors of remote experiments can choose from several design systems, including the hardware and software components for their implementation. All remote real experiments developed at the Trnava University, Faculty of Education, Department of Physics are designed on the ISES basis.

ISES is an experimental computer measurement system that was originally developed to support the teaching of physics using computer-assisted experiments in the laboratory [4]. Thanks to the wide range of measurement components, it can also be used in the educational process of other subjects, such as chemistry, biology or technical subjects. It is an open system operating under Windows and using all its benefits. It is designed to measure, record, store, process and present data. ISES consists of three main parts, which are shown in Fig. 1.

Measurement modules (such as a probe) are used to record various physical quantities. The probe reads the value of the measure, and in the form of an electrical signal delivers it to the module, which serves as an information intermediary between the probe and the control panel. The second part is the control panel enabling the connection of multiple measurement modules. It reads all the information from the connected components and sends them to the host computer through the internal input-output ADDA card. The last part is the ISESWin software, which processes the received data into the desired form, thus enabling communication with individual modules as well as storage, processing and presentation of the data measured.

When developing a real remote experiment, step 1 is to create a computer-aided experiment by using ISES. Step 2 is arranging a conventional server-client connection, enabling data transfer to the client and in the opposite direction to control the experiment [5].

The ISES WEB Control software serves to support the remote measurement and management. The server side consists of a computer, which is connected to the ISES measurement system, Windows environment, any web server and tree server modules: ImageServer, MeasureServer, HTTPRelayServer. Intermediaries of communication on the website are the applets allowing the development of the control components in accordance with the Java options. They are used to measure and display the input variables in digital and graphic forms. Other applets are designed to transmit measured data between the server and the user's computer, transferring images from web cameras and other options [6].

ISES WEB Control software installs all the necessary components of a remote experiment as finite states of the machine. The end state of the machine is a mathematical model used to calculate the proposal for computer programs and sequential logic circuits.

It is designed as an abstract machine that can be in one of a finite number of states. It may occur at the time it is precisely in one of the states, which then is called the current state.

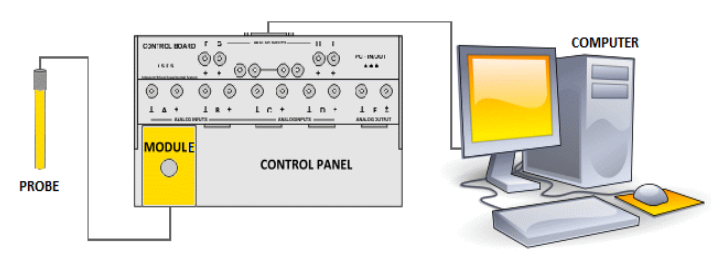

Figure 1. Parts of ISES system Ref. [7]

The transition between states is called a change from one state to another. It occurs in the beginning of the implementation of the activating events or conditions. The final states of the machine are defined by a list of all the states and conditions for transitions. The finite state of the machine built on ISES creates a control program for the specific functions of the remote experiment, called psc file corresponding to the website on the client side [1].

In this section, we dealt with the issue of developing remote experiments. Making a psc file is not easy and requires special knowledge of the programming language created for this purpose. All remote experiments using ISES, which were developed in 2012, use this psc file. The team of Schauer, Krbeček, Lustig [1] came up with the idea of simplifying the remote experiments by using the new environment of ER ISES. This environment was applied to program and pilot the Archimedes' Principle eexperiment. In the next section, we will briefly describe the ER ISES environment.

\section{EASY REMOTE ISES}

ER ISES is a graphic development environment that automatically generates the control psc file for the finite states of the machine [1].

After installing the program, the three icons used in the process of the development are displayed in the given folder (Fig. 2a-c). The ER ISES icon launches the interface of the development environment. The Start icon starts the experiment, and the Stop icon stops it. After running the ER ISES, a welcome menu appears on the computer desktop. It offers a choice of three control panels ER ISES (Fig. 3) displayed as pictures.

Selection must correspond to the control panel, which is actually physically connected to the experiment. In the introductory window, users can also change the language and open saved projects.

The development environment offers three levels of difficulty, from the easiest (beginner) (Fig. 4) level through basic up to the advanced one. Individual levels of difficulty will be discussed in detail below.

The easiest way to develop remote experiments is at the beginner level. Data are exported from the preprogrammed library of experiments, from which the user selects the desired component.

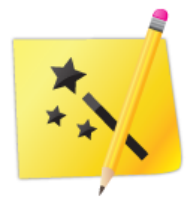

a)

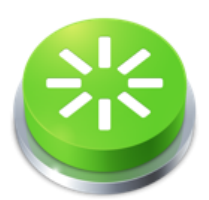

b)

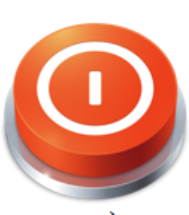

c)
Figure 2. ER ISES icon a), Start icon b), Stop icon c) [1] 


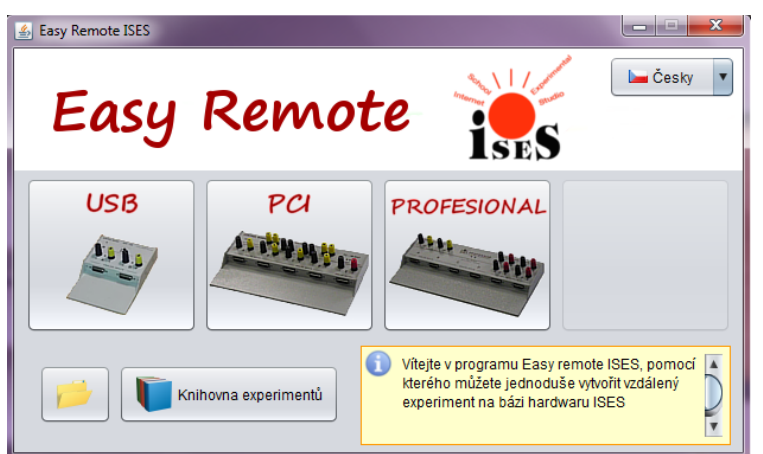

Figure 3. ER ISES - introductory menu [1]

The beginner level window is divided into four parts: in the upper left corner, there is a list of experiments; on the right, individual descriptions are displayed; while the layout and design of the final website experiment can be previewed in the lower left corner of the window.

If users are satisfied with the resulting remote experiment, they can press the Finish button, and the program generates the necessary components and returns to the original start menu. The experiment accomplished in this way is operational and users can work with it [1].

If selecting the basic level, the window in which users can assign required modules to each slot of the ISES control panel using the drop-down bars is displayed.

If using the relay board, its parameters can be set up by clicking the Relay board, selecting the relay connections in the newly opened window in the form of pictures of the board. The program automatically asks for details of the individual relay settings.

The next step is setting up the website design and adding inputs and outputs of the experiment.

In the left part of the window, users enter the name of the experiment; underneath is the IP address that will be globally accessible via the Internet. If users want to only run the experiment locally, they tick the related box. In such cases, it is available only on the computer on which it was installed and runs on the internal IP address 127.0.0.1, also referred to as localhost.

Furthermore, users can customize the appearance of the resulting web page by adding logos and the scheme of experiment as well as changing the background colours, headers and footers. On the right, there are two fields with colour-coded inputs and outputs. Red are inactive modules, namely those that have not been assigned any activity yet.

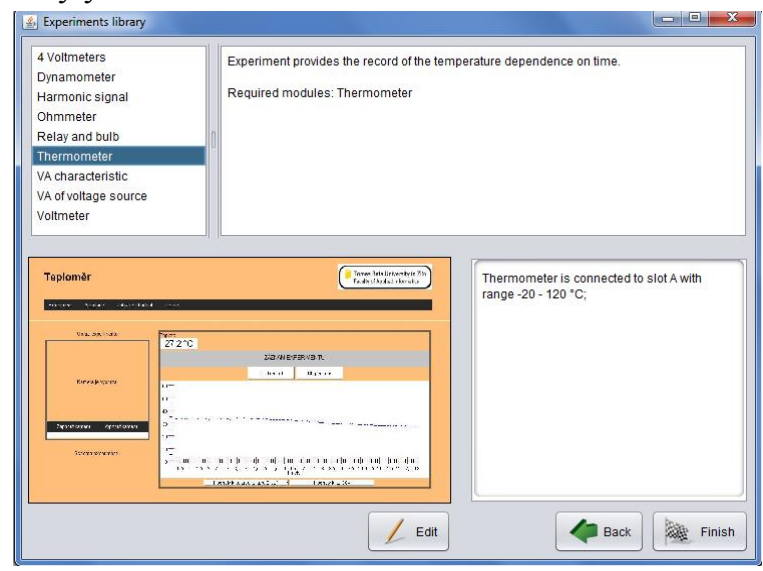

Figure 4. ER ISES - level beginner [1]
The active modules are blue. At denoting a module and then pressing the Add applet button, the displayed window offers several options of data representations.

When clicking the Layout tab website, a window is displayed that contains a tree structure on the left, with all associated activities, i.e. titles, buttons, other controls or graphs (Fig. 5). By moving the elements in the structure or adding lines, users can change the layout of the resulting website [1].

Completion of modifications and starting the remote experiment are performed by pressing the Finish button. Similar to the beginner level, the interface switches to the start menu, and the experiment is ready to run.

As for the advanced level of the program, users press the option Advanced design in the window of module selection. After doing so and then pressing Next, a window of psc advanced design appears (Fig. 6). Its major part is a tree structure of the psc file representing the control logic of the experiment. On the right side, there is a list of commands and mathematical functions. Underneath is a list of variables with buttons for adding or removing. Insertion of these lists is done by dragging and dropping; users select the desired element and put it where needed by clicking in the tree structure. While inserting, it is necessary to follow the rules of placement and superiority and subordination of elements.

To assist users, there is a light brown (or orange) text box in the windows, displaying the information about the elements. When developing the Archimedes' Principle remote experiment, we worked with an advanced level of design.

When developing a remote experiment, we suggest saving the design of the development environment. In case of errors, the store information may shorten the process of design. The offer is available in the last window of the website design. The experiment will be stored in a file with the suffix ers. Users can open it in the starting menu by clicking the icon of the file or the pop-up menu under Open.

The experiment is displayed in the initial phase of the design; during the transition to the next steps, the data are stored in the appropriate positions, as they were at the time of saving the project.

The graphical development environment of ER ISES is currently fully operational in a beta-version.

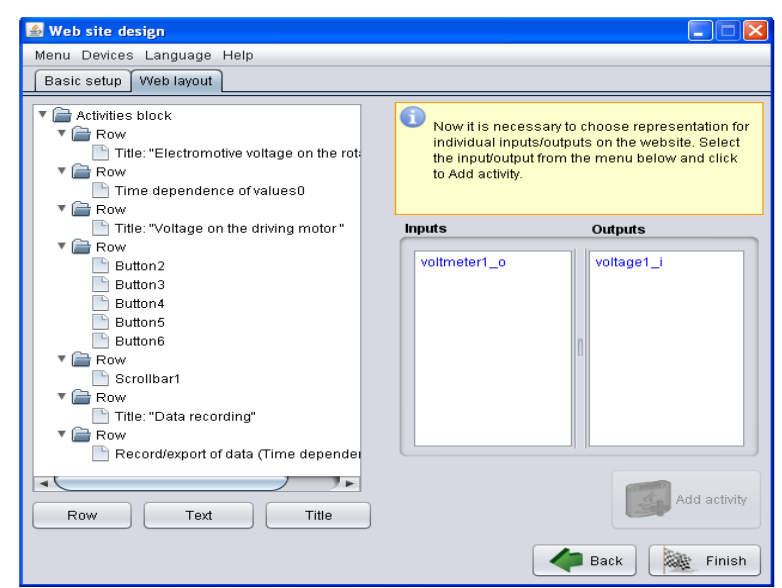

Figure 5. ER ISES - website layout [1] 


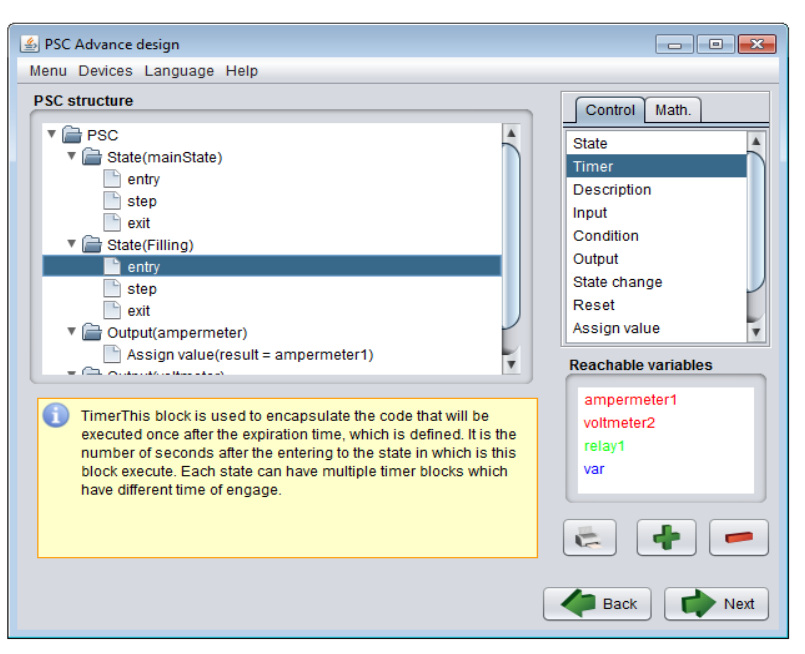

Figure 6. ER ISES - PSC Advanced design [1]

It is suitable for developing remote experiments without the need for special programming skills. The authors intend to present this tool for program design online in the form of e-shops on both hardware and software.

A library of the experiments currently stored on the local disk will be available in the future on a web server in the data centre. The library will allow users to download the experiments and upload them into the server memory. The online library of experiments will thus offer an ever expanding range of new experiments developed by users.

\section{DESIGN AND STRUCTURE OF REMOTE EXPERIMENT ARCHIMEDES`PRINCIPLE}

Hardware configuration of the Archimedes' Principle remote experiment is shown in Fig. 7. It comprises the following components:

\section{1) Experimental device}

In Fig. 8, a device consisting of a sliding base (a) with three containers of liquid (b) is shown. The movement of the base with the containers is driven by the motor (not seen in figure). The movement can be performed vertically along the $y$-axis up and down. Switches (c) in the terminal positions can stop the movement. Attached to the ISES dynamometers (d), the examined solids (e) are dipped into the liquid when the containers move upward, and they emerge when the containers return to the starting position. The position of the base is determined by a tight wire connected to a DC voltage source and a detector that moves simultaneously with the base and measures voltage

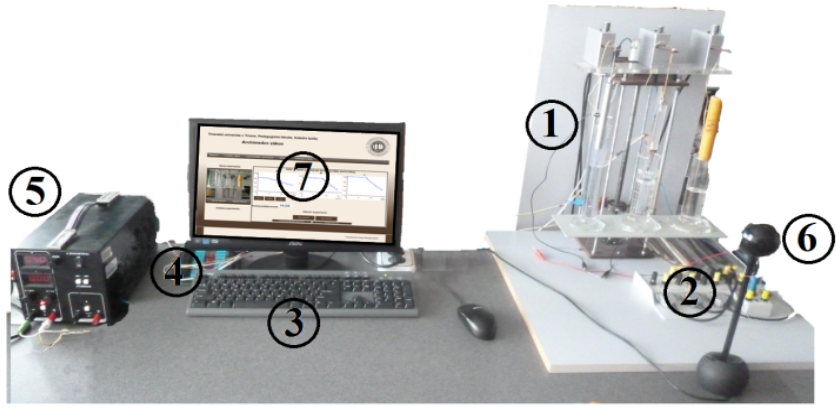

Figure 7. Experimental arrangement of Archimedes' Principle: 1- Experimental device, 2 - ISES control panel, 3 - Managing computer, 4 - Relay board, 5 - Power source, 6 - Camera, 7 - Web interface using a voltmeter of the ISES set. In Fig. 8, users can see the current bodies (aluminum with a mass $66.4 \mathrm{~g}$, perspex of mass $36.9 \mathrm{~g}$ and plastic with a mass $88.2 \mathrm{~g}$ ) that are immersed in the colored water.

\section{2) ISES control panel}

Experimental data are made available by the ISES experimental measurement system. Three dynamometers modules are used for measurement of the magnitude of the resultant force acting on the solid. A module of voltmeter is used for determination of the base position. The modules are connected to the ISES control panel.

\section{3) Managing computer}

The ISES control panel is connected to the managing computer through the internal input-output ADDA card. The computer can locally control the course of the experiment.

\section{4) Relay board}

It is connected to the managing computer; using relays, it controls vertical movement along $y$-axis.

\section{5) Power source}

The experiment is driven by the voltage source, which is set up to $6 \mathrm{~V}$.

\section{6) Camera}

It captures a real-time video, which is shown in the window of the web interface.

\section{7) Web interface}

The web interface is generated in the ER ISES software. It allows remote control of operations, data recording and collection at any time and at any place where there is a connection to the Internet.

In the early stage, we designed a scheme of the web interface structures. After pilot testing of the web interface, we added new elements, as seen in Fig. 9. The schematic elements mean the following:

- Clear - is represented by the button used to delete the curves from the graph after repeated measurements;

- Web camera - a window with the output of the web camera placed in front of the experiment and sensing its current state;

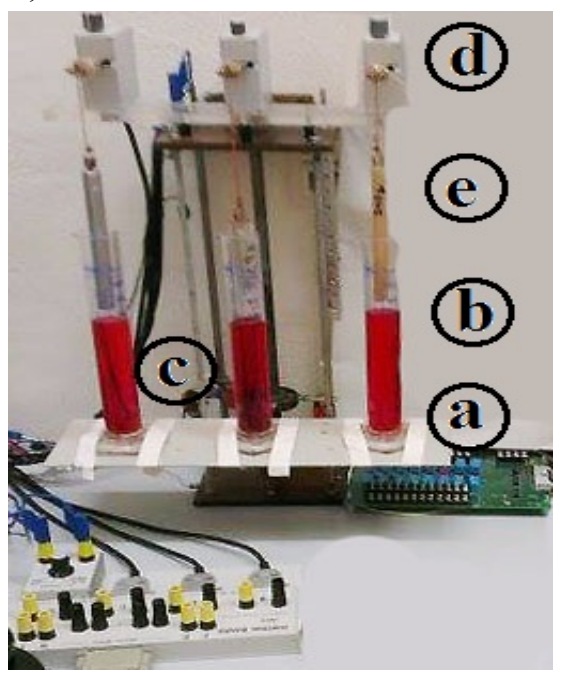

Figure 8. Detail of Experimental device: a) sliding base, b) three containers of liquid, c) switches, d) ISES dynamometers, e) examined solids suspend on a ropes 
- Graphs $A, B, C$-where the curve of the dependence of total force or of buoyant force as a function of the position of the base of the competent tubes will be plotted;

- $U p$ - is represented by the button used to start the upward movement of the base, i.e. immersion of the solids;

- Stop - the button used to stop the movement of the base;

- Down- is used to start the downward movement of the base and, thus, the emergence of the solids;

- Position of the base - the text field for typing in the current position of the base in centimeters; the lower limit position is zero;

- Total force - the button to start the measurement of the total force as a function of the position of the base of the competent tubes;

- Buoyant force - the button to start the measurement of the buoyant force as a function of the position of the base of the competent tubes;

- Start of recording - the button to start the recording of the data;

- Stop of recording - the button to stop the recording of data;

- CSV Export - the button used to export the recorded data to the users' computers in the form of a csv file;

- Excel Export - the button for exporting the recorded data into computer in XML, which is supported by MS Excel.

The text outside the box in the design of the experiment structure symbolizes text descriptions posted on the website.

When designing the web interface, we tried to adhere to the structure. But since ER ISES is also designed for nonprogrammers and has some predefined elements with typical arrangement, the resulting experiment is slightly different from the proposal.

\section{DESIGNING THE EXPERIMENT IN ER ISES}

After preparing the structure of the experiment web interface and developing the flowchart, we could start programming. The Archimedes' Principle remote real experiment was designed in the beta version of the ER ISES development environment in the following steps:

We launched the program by double clicking on the ER ISES icon and selecting PCI control panel. In the window, we assigned the modules necessary for the experiment to the ISES control panel.

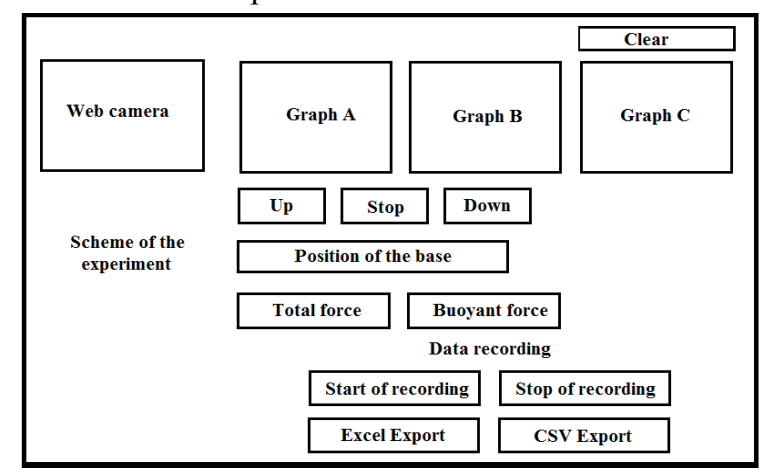

Figure 9. Structural design of remote experiment - Archimedes' Principle
The dynamometers are connected with slots A, B, C, while a voltmeter is connected in slot D. After selecting a module, its photo appears in the relevant slot (Fig. 10). We then modified the scope of the measuring device (to reflect reality) by means of the bar underneath the relevant slot. In the next step, we pressed the Relay board; the new window displayed its image and we checked the relays used. The experiment utilized Relay 1, Relay 3 and Relay 5. After pressing the Advanced design, we moved to another window in which we developed a mathematical description of the experiment, which is deposited as a psc file.

In the first step, we declared variables we wanted to work with. We chose the variable control smer_tacidlo (direction), to which the value was assigned by means of the buttons. In the status step, we wrote conditions under which we would evaluate the truth of the variable control_smer_tlacidlo. At pressing the $U p$ button, i.e. movement upwards, control_smer_tlacidlo was assigned the value 25 , which satisfied the first condition in our algorithm. Thus, the commands in the condition began to work. They were assigned to the variables relay via binary values, interpreted as 1 relay is on and 0 relay is off. Pressing buttons Stop and Down created similar conditions, but with different values. For button Total force and button Buoyant force, we declared variable control_graf_tlacidlo (graph), to which the value was assigned by similar conditions. To work with the variables, we inserted them into the output within the psc file.

After developing the mathematical model, we moved to the website design window, where we selected the option of advanced design (Fig. 11).

First, we gradually inserted applets for inputs and outputs of the experiment. Inputs of the designed project are the buttons of movement. They are inserted by clicking the input where the variable control_smer_tlacidlo was entered in the previous section.

Then we pressed the Add applet button. A new separate window provided the input button, vertical or horizontal scroller. Then we selected a button and clicked on the Insert onto website button. It opened the menu where we could choose the method of using the button. Then we filled in the table with the properties, assigned value to the key (in the form of a variable) and entered the description displayed in it.

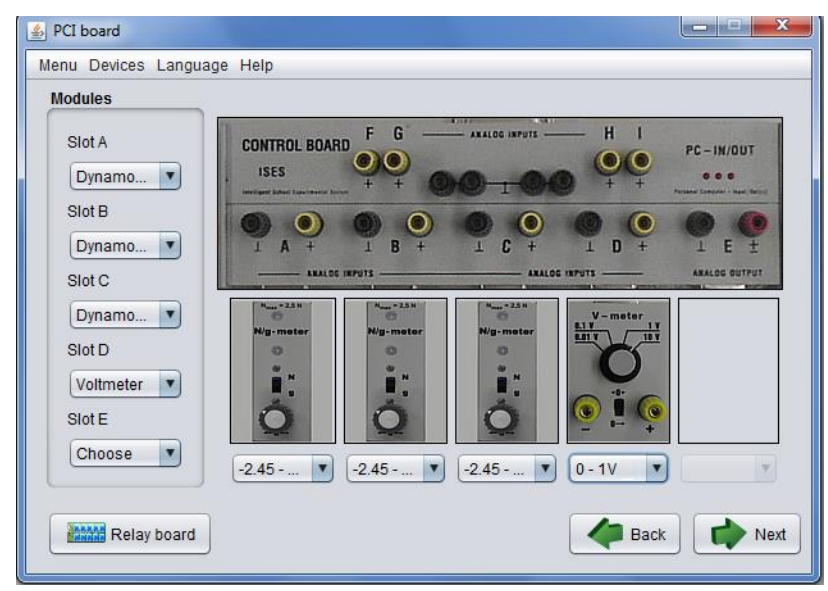

Figure 10. ER ISES - PCI board 


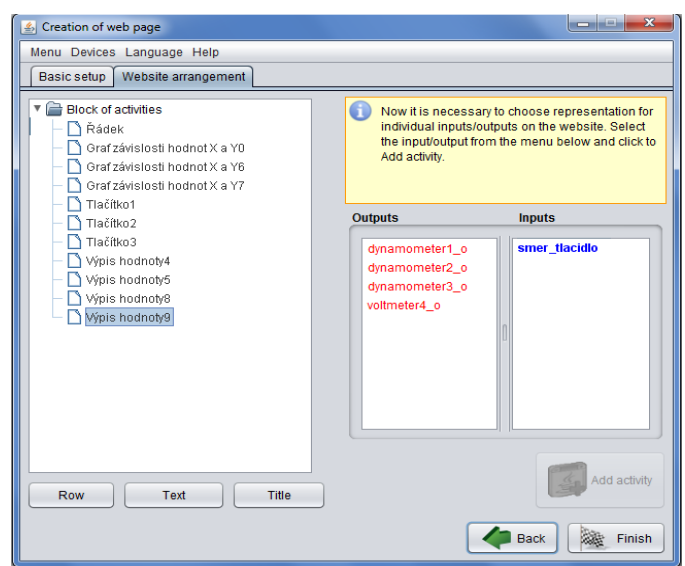

Figure 11. ER ISES - design of the website

When inserting the outputs, we continued similarly to the inputs. We clicked on the output to be displayed and pressed Add applet. It opened a new window that offered eight representations of the measured data either in the form of a statement of digital value, graphical dependence of two variables, graphical dependence of one to four variables on time, and data records. The reading could be either a time one, recording one variable dependent on time, or a record of two variables selected on the axis. This applet includes the buttons for starting and stopping the recording as well as the buttons allowing the export of data to the users' computers in the form of csv and excel files.

Currently the experiment contains the three graphs of the resulting force (total force or buoyant force) depending on the position of the base for the individual tube (immersion depth), an applet to record and export readings, buttons for controlling experiment and a digital record of real values.

In the next step, we moved to the window of the basic settings of the webpage, where we entered the name of the experiment and stored it before running.

We checked the box indicating that we wanted to run the experiment locally and then pressed the Finish button. We ran the designed web page of the experiment by using a web browser and entering the internal IP address 127.0.0.1.

Fig. 12 displays the resulting image of the website of the remote experiment Archimedes' Principle after finishing the immersion of solids into the liquids, along with related diagrams.

The experiment Archimedes' Principle is available online at http://remotelab9.truni.sk within the first Slovak remote physics laboratory at the University of Trnava, Department of Physics.

At present, the e-laboratory provides one chemistry experiment: an electrochemical cell, and ten physics experiments that are freely available at http://remotelabN.truni.sk, where $\mathrm{N}=1,2,10$ or http://kf.truni.sk/remotelab. The experiments in the eLaboratory are constantly being improved, enhanced and expanded with new experiments, e.g. the Joule experiment. This experiment at present is running in hands on mode and soon will be converted to its remote counterpart under the address http://remotelab11.truni.sk [8],[9],[10],[11].

The laboratory is currently available in two languages, English and Slovak. The hardware and software solutions of experiment are provided using an ISES platform.

The only system requirement for the user is to have a computer with an installed JRE plug-in, since the experiment is available on the web page with Java applets. And, of course, an Internet connection is a must. The Java Runtime Environment (JRE) is a set of software tools for development of Java applications. It combines the Java Virtual Machine, platform core classes, supporting libraries and components, which are necessary to run programs written in Java.

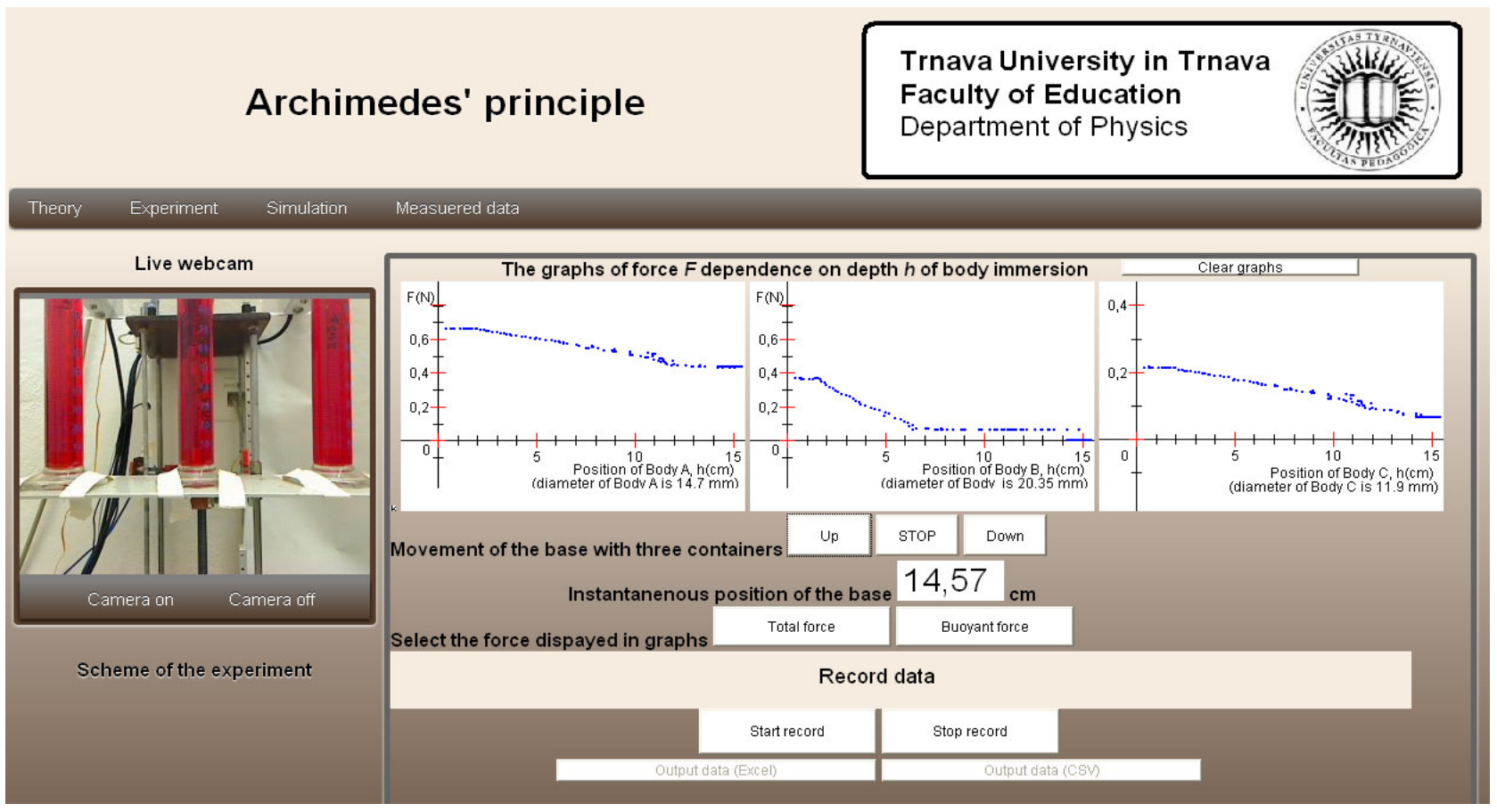

Figure 12. Website of the Archimedes' Principle remote experiment 


\section{CONCLUSION}

For this project, we developed a web interface for the real remote experiment of the Archimedes' Principle based on ER ISES, available at http://remotelab9.truni.sk. The current implementation is not considered final. Its improvement and testing will continue. Programming the environment of the ER ISES is also under development and refinement, with bright prospects for the future.

We are preparing the pilot implementation of this experiment not only into university level education, but also for secondary and primary physics education via the strategy of Integrated e-Learning [12], [13] because the Archimedes' Principle is one of the laws of physics used most in real life applications in both gas and liquid environments. Although it is application rich, deep understanding of its physical background is often overshadowed by misconceptions.

As mentioned above, the presented e-experiments utilize Java applets. Unfortunately, under recent operation conditions of Java applets and due to the tightening security rules for web browsers, problems with Java applets in remote experiments were discovered. For running these experiments you need to downgrade Java to version 6 or lower.

We are working hard to solve the problem and gradually applets are being overwritten to JavaScript.

\section{ACKNOWLEDGMENTS}

The authors would like to thank the Grant Agency of the Ministry of Education of the Slovak Republic - KEGA No. 020TTU-4/2013 "Accreditation of personalized ICT natural sciences teacher's education centre" and No. 011TTU4/2012 "Energy as a Category in Science Education via remote experiments and Integrated e-Learning" and Grant of the Trnava University in Trnava No. 10/TU/13 "Energy in the teaching of the physics with using the remote experiment."

Special thanks go to Prof. F. Schauer, DrSc. and Ing. M. Krbeček of Tomas Bata University in Zlín and Assoc. Prof. RNDr. F. Lustig, CSc. of Charles University in Prague for providing ER ISES software.

\section{REFERENCES}

[1] M. Krbeček, F. Schauer, F. Lustig. "Easy Remote ISES Environment for Remote Experiments Programming", Innovations 2013: World Innovations in Engineering Education and Research, W. Aung, et al. (eds.), iNEER, Potomac, MD, USA, pp. 80 - 101.

[2] T. L. Heath, Archimedes. London Society for Promoting Christian Knowledge, 1920. Available on the Internet: $<$ https://archive.org/details/worksofarchimede $029517 \mathrm{mbp}>$

[3] D. Halliday, R. Resnick, J. Walker. "Fundamentals of Physics" $6^{\text {th }}$ ed. Wiley, 2000, pp. 466, ISBN 978-0471332367.
[4] K. Žaková, M. Sedlák, "Remote Control of Experiments via Matlab", Int. Journal of Online Engineering (iJOE), vol. 2, no. 3, 2006.

[5] F. Schauer, F. Lustig,, J. Dvořák, M. Ožvoldová. "Easy to build remote laboratory with data transfer using ISES-Internet School Experimental System". European Journal of Physics. 29, 2008, pp. 753-765, ISBN 978-0-9741252-9-9.

[6] F. Lustig, "Jak si jednoduše postavit vzdálenou laboratoř na internet (How to simply build a remote laboratory on teh Internet)". Veletrh nápadi̊ učitelu fyziky (Swap shop of Physics teachers). Brno. 2004, pp. $9-19$. Available on the Internet: $<$ http://vnuf.cz/sbornik/prispevky/09-19-Lustig.html $>$.

[7] http://www.ises.m-fit.com/ises.html

[8] M. Ožvoldová et al., "e-Laboratory“, http://kf.truni.sk/remotelab.

[9] Ž. Gerhátová, P. Čerňanský, L. Tkáč, F. Schauer, "Remote Experiment in Chemistry for Science Education" MPTL16 - HSCI 2011. - Ljubljana: The Hands-on Science Network, 2011. pp. 2832. ISBN978-989-95095-7-3.

[10] L. Tkáč, F. Schauer, Laboratory work by remote experimentation in distance education "Innovations 2013: World Innovations in Engineering Education and Research, W. Aung, et al. (eds.), iNEER, Potomac, MD, USA, pp. $101-123$.

[11] L. Tkáč, F. Schauer, Ž. Gerhátová. Remote experiment on characterization of energy transducers, In: Proceeding of the $11^{\text {th }}$ REV Conference $-11^{\text {th }}$ International Conference on Remote Engineering and Virtual Instrumentation, Porto, Portugal, 26.- 28. February 2014, pp. 248-253, isbn 978-1-4799-2025-9.

[12] M. Kostelníková, Ž. Gerhátová. Reálne, reálne vzdialené a virtuálne experimenty $\mathrm{v}$ základnej škole - prostriedok na prezentovanie javov reálneho sveta (Real, real remote and virtual experiments in primary school- means for real world phenomena presentation). In Sapere Aude 2012: Vzdélávaní a dnešni společnost [CD-ROM]. Hradec Králové: Magnaminitas, 2012. s. 141-150. ISBN 978-80-904877-9-6.

[13] F. Schauer, M. Ožvoldová, F. Lustig, "Integrated e-learning - new strategy of the cognition of real world in teaching". World Innovations in Engineering Education and Research iNEER. USA. Special Volume 2009. pp. 119.-135. Available: $<$ http://www.ises.info/ises data/publications/Schauer INTEL fin.p df $>$

\section{AUTHORS}

M. Ožvoldová is with the Trnava University in Trnava, Faculty of Education, Priemyselná 4, SK- 918 43, Trnava, Slovak Republic (e-mail: mozvoldo@truni.sk), and Tomas Bata University in Zlin, Faculty of Applied Informatics, T.G. Masaryk sq. 275, Zlín CZ-76272, Czech Republic.

P. Špiláková is with Tomas Bata University in Zlin, Faculty of Applied Informatics, T.G. Masaryk sq. 275, Zlín CZ-76272, Czech Republic (petra.spilakova@gmail.com),

L. Tkáč with the Trnava University in Trnava, Faculty of Education, Trnava University in Trnava, Priemyselná 4, SK91843, Trnava, Slovak Republic (tkac.lucas@gmail.com),

Submitted 30 April 2014. Published as resubmitted by the authors 13 September 2014 